\title{
Effects of CuO nanoparticles on Lemna minor
}

\author{
Guanling Song ${ }^{1,2}$, Wenhua Hou ${ }^{3}$, Yuan Gao ${ }^{4}$, Yan Wang ${ }^{1 *}$, Lin Lin' ${ }^{1}$, Zhiwei Zhang ${ }^{1}$, Qiang Niu', Rulin Ma', \\ Lati $\mathrm{Mu}^{1}$ and Haixia Wang ${ }^{1}$
}

\begin{abstract}
Background: Copper dioxide nanoparticles (NPs), which is a kind of important and widely used metal oxide NP, eventually reaches a water body through wastewater and urban runoff. Ecotoxicological studies of this kind of NPs effects on hydrophyte are very limited at present. Lemna minor was exposed to media with different concentrations of $\mathrm{CuO}$ NPs, bulk $\mathrm{CuO}$, and two times concentration of $\mathrm{Cu}^{2+}$ released from CuO NPs in culture media. The changes in plant growth, chlorophyll content, antioxidant defense enzyme activities [i.e., peroxidase (POD), catalase (CAT), superoxide dismutase (SOD) activities], and malondialdehyde (MDA) content were measured in the present study. The particle size of CuO NPs and the zeta potential of CuO NPs and bulk CuO in the culture media were also analyzed to complementally evaluate their toxicity on duckweed.
\end{abstract}

Result: Results showed that CuO NPs inhibited the plant growth at lower concentration than bulk CuO. L. minor roots were easily broken in CuO NPs media under the experimental condition, and the inhibition occurred only partly because $\mathrm{CuO}$ NPs released $\mathrm{Cu}^{2+}$ in the culture media. The POD, SOD, and CAT activities of L. minor increased when the plants were exposed to $\mathrm{CuO} N P s$, bulk CuO NPs and two times the concentration of $\mathrm{Cu}^{2+}$ released from CuO NPs in culture media, but the increase of these enzymes were the highest in CuO NPs media among the three kinds of materials. The MDA content was significantly increased compared with that of the control from $50 \mathrm{mg} \mathrm{L}^{-1} \mathrm{CuO} \mathrm{NP}$ concentration in culture media.

Conclusion: $\mathrm{CuO}$ NPs has more toxicity on L. minor compared with that of bulk $\mathrm{CuO}$, and the inhibition occurred only partly because released $\mathrm{Cu}^{2+}$ in the culture media. The plant accumulated more reactive oxygen species in the CuO NP media than in the same concentration of bulk CuO. The plant cell encountered serious damage when the $\mathrm{CuO} \mathrm{NP}$ concentration reached $50 \mathrm{mg} \mathrm{L}^{-1}$ in culture media. The toxicology of CuO NP on hydrophytes must be considered because that hydrophytes are the basic of aquatic ecosystem.

\section{Background}

Nano-technology has a strong claim to be regarded as the first important advance in technology of the third millennium (Robert 2012). Given the rapid development of nanotechnology, an increasing risk of human and environmental exposure to nanotechnology-based materials is apparent. However, data on the potential environmental effects of nanoparticles (NPs) are scarce (Clément et al. 2013; Zhang et al. 2013), particularly on the effects

\footnotetext{
*Correspondence: keaiwangyan.student@sina.com

1 School of Medicine, Shihezi University, Shihezi 832000, China

Full list of author information is available at the end of the article
}

and mechanisms of these NPs on higher plants (Nair et al. 2010; Song et al. 2012; Miralles et al. 2012).

Metal oxide NPs are manufactured at a large scale for both industrial and household use (Aitken et al. 2006; Xia et al. 2013). CuO NPs, an important kind of metal oxide NPs, are used in catalysis, gas sensors, solar energy conversion, high-temperature superconductors, and fieldemission emitters (Chowdhuri et al. 2004; Yin et al. 2005; Dar et al. 2008; Jammi et al. 2009). With such large-scale applications, $\mathrm{CuO}$ NPs will inevitably reach bodies of water through waste water and urban runoff. Therefore, understanding the risks of this kind of NPs to aquatic ecosystems is essential. The toxicity study of CuO NPs on aquatic organisms has drawn considerable attention

\section{贷 Springer}

(c) 2016 Song et al. This article is distributed under the terms of the Creative Commons Attribution 4.0 International License (http://creativecommons.org/licenses/by/4.0/), which permits unrestricted use, distribution, and reproduction in any medium, provided you give appropriate credit to the original author(s) and the source, provide a link to the Creative Commons license, and indicate if changes were made. 
in recent years. Aquatic creatures, such as fish, algae, bacteria, and crustaceans, are adversely affected by $\mathrm{CuO}$ NPs (Kahru and Dubourguier 2010; Gunawan et al. 2011; Zhao et al. 2011; Li et al. 2012). However, the toxic effects of $\mathrm{CuO}$ NPs on hydrophytes are scare at present. Aquatic macrophytes are important for oxygen production, nutrient cycling, water quality control, sediment stabilization, and shelter for aquatic organisms and wildlife (Mohan and Hosetti 1999); these plants are vital in maintaining the stability of aquatic ecosystems. Thus, the toxic effect of $\mathrm{CuO}$ NPs on aquatic plants should be studied on time.

Lemna minor, a duckweed species, is a widespread, free-floating aquatic macrophyte. L. minor is a food source for waterfowl and a shelter for small aquatic invertebrates. L. minor grows fast and reproduces more rapidly than other vascular plants. Because of these characteristics, duckweed is often used in water body restoration and ecotoxicological studies (Song et al. 2012; Žaltauskaité and Norvilaitė 2013). To study the toxicity effect of $\mathrm{CuO}$ NPs on L. minor, the macro growth and microphysical response of $L$. minor exposed to CuO NPs in several concentrations were investigated compared with those of $L$. minor exposed to bulk $\mathrm{CuO}$ and soluble $\mathrm{Cu}^{2+}$. These physical indexes include the peroxidase (POD), catalase (CAT), and superoxide dismutase (SOD) activities of this floating plant, as well as its malondialdehyde (MDA) and chlorophyll contents, under different treatments.

\section{Methods}

Plant materials, growth conditions, and treatment procedures

L. minor was collected from the region of Shandong Province in China (N $36^{\circ} 48.183^{\prime}$, E $\left.117^{\circ} 55.528^{\prime}\right)$. The plant was stored in glass troughs $(0.5 \mathrm{~m} \times 0.8 \mathrm{~m} \times 0.6 \mathrm{~m})$ and illuminated with metal halide lamps $\left(72 \mu \mathrm{mol} \mathrm{m} \mathrm{m}^{-2} \mathrm{~s}^{-1}\right)$ as pre-treatment during a daily photoperiod of approximately $16 \mathrm{~h}$ for 1 month before the experiments. The pretreatment medium was 1/10 modified Steinberg medium (Michael and Hans-toni 2002) (Table 1) with a pump for circulation, and the culture was maintained at $26 \pm 2{ }^{\circ} \mathrm{C}$. The medium was renewed with the same concentration of modified Steinberg medium every two weeks.

\section{Characterization of CuO NPs and bulk CuO}

$\mathrm{CuO}$ NPs and bulk $\mathrm{CuO}$ were purchased from Shanghai Jingchun Reagent Limited Company, China. CuO NPs, with the purity is greater than $99.5 \%$, particle diameter is $40 \mathrm{~nm}$ and a surface area is $25-40 \mathrm{~m}^{2} \mathrm{~g}^{-1}$. The purity of bulk $\mathrm{CuO}$ is more than $99.9 \%$, particle diameter is $10 \mu \mathrm{m}$. The morphology of the CuO NPs was examined by transmission electron microscopy (TEM, JEOL 100CX, Japan). The particle diameter of $\mathrm{CuO}$ NPs in solution and the
Table 1 Composition of the modified Steinberg medium

\begin{tabular}{ll}
\hline Substance & $\begin{array}{l}\text { Concentration } \\
\left(\mathbf{m g ~ L}^{-} \mathbf{1}\right)\end{array}$ \\
\hline $\mathrm{KNO}_{3}$ & 350 \\
$\mathrm{KH}_{2} \mathrm{PO}_{4}$ & 90 \\
$\mathrm{~K}_{2} \mathrm{HPO}_{4}$ & 12.6 \\
$\mathrm{MgSO}_{4} 7 \mathrm{H}_{2} \mathrm{O}$ & 100 \\
$\mathrm{Ca}\left(\mathrm{NO}_{3}\right)_{2} 4{ }_{2} \mathrm{HO}$ & 295 \\
$\mathrm{MnCl}_{2} 4 \mathrm{H}_{2} \mathrm{O}$ & 0.18 \\
$\mathrm{H}_{3} \mathrm{BO}_{3}$ & 0.12 \\
$\mathrm{Na}_{2} \mathrm{MoO}_{4}$ & 0.044 \\
$\mathrm{ZnSO}_{4} 7 \mathrm{H}_{2} \mathrm{O}$ & 0.18 \\
$\mathrm{FeCl}_{3} 6 \mathrm{H}_{2} \mathrm{O}$ & 0.76 \\
$\mathrm{Na}_{2} \mathrm{EDTA}_{2} \mathrm{H}_{2} \mathrm{O}$ & 1.5 \\
\hline
\end{tabular}

zeta potential of $\mathrm{CuO}$ NPs and bulk $\mathrm{CuO}$ in solution were measured using a 90 plus particle size analyzer (DR-525, Brookhave Instruments Corporation, USA) at $12 \mathrm{~h}$ after media preparation. The $\mathrm{Cu}^{2+}$ concentration that the nano$\mathrm{CuO}$ released to the culture media was measured by ICPMS 7500 ce, Agilent, USA at $24 \mathrm{~h}$ after media preparation.

\section{Test design}

The experiment media were divided into three treatments. The media for treatment 1 consisted of $1 / 10$ modified Steinberg medium with $0,10,50,100,150$, and $200 \mathrm{mg} \mathrm{L}^{-1} \mathrm{CuO}$ NPs, which were ultrasonicated for $30 \mathrm{~min}$. The media for treatment two consisted of $1 / 10$ modified Steinberg medium with 0, 10, 50, 100, 150, and $200 \mathrm{mg} \mathrm{L}^{-1}$ bulk $\mathrm{CuO}$. The media for treatment three were 1/10 modified Steinberg medium with an amount of $\mathrm{CuCl}_{2}$ that supplied twice the $\mathrm{Cu}^{2+}$ concentration released from $\mathrm{CuO}$ NPs in treatment 1 media. The tests were performed in $500 \mathrm{~mL}$ beakers containing $200 \mathrm{~mL}$ media. The $\mathrm{pH}$ of all of the culture media was adjusted to 6.5 .

Before the experiments, $L$. minor was disinfected by immersing in $\mathrm{NaClO}(1 \%, \mathrm{v} / \mathrm{v})$ for 3 to $5 \mathrm{~min}$, and then rinsing with distilled water for three times. Culture media were renewed every 2 days. The cultured $L$. minor was divided into two groups with different treatments. Each treatments contain three replicates. The inoculum of the first group included 12 fronds (only plant with two or three fronds were selected), which were used in determining the number of fronds, root length, and fresh weights at $96 \mathrm{~h}$. The inoculum of the other group included $1 \mathrm{~g}$ of fronds (measured after $5 \mathrm{~min}$ of blotting on dry tissue paper), which were used in determining the chlorophyll, POD, CAT, SOD, and MDA at $96 \mathrm{~h}$. The plants in all of the groups and treatments were randomly placed together in a growth chamber with $60 \%$ humidity at $28^{\circ} \mathrm{C}$ in the light $\left(36 \mu \mathrm{mol} \mathrm{m}{ }^{-2} \mathrm{~s}^{-1}\right)$ and at $26^{\circ} \mathrm{C}$ in the 
dark. The phytotoxicity experiment lasted for 4 days. The suspensions were stirred using a glass rod every $8 \mathrm{~h}$. The change in the number of fronds is calculated according to the following formula (Tkalec et al. 1998; Song et al. 2006).

The change of frond number

$$
=\frac{\text { no. of fronds at day } \mathrm{n}-\text { no. of fronds at day } 0}{\text { no. of fronds at day } 0}
$$

\section{Enzyme extraction and chlorophyll determination}

To obtain the enzyme extract, $500 \mathrm{mg}$ of whole plant was homogenized in $5 \mathrm{~mL}$ cold potassium phosphate buffer (0.1 M, pH 7.8). The homogenate was centrifuged at $15,000 \mathrm{~g}\left(4^{\circ} \mathrm{C}\right)$ for $15 \mathrm{~min}$ in a refrigerant centrifuge. The supernatant was used as the enzyme extract. The enzyme extraction was conducted at $4{ }^{\circ} \mathrm{C}$.

Chlorophyll content was measured using the duckweed fronds. The fronds were whetted and distilled in ethanol (96\%), and then the extracts were measured spectrophotometrically at 665, 649, and $470 \mathrm{~nm}$ (Zhao 2000a).

\section{Enzyme assays}

For POD, the mixture consisted of $50 \mathrm{mM}$ potassium phosphate buffer ( $\mathrm{pH} 7.0$ ), $1 \mathrm{~mL} ; 0.2 \% \mathrm{H}_{2} \mathrm{O}_{2}, 2 \mathrm{~mL}$; $0.2 \%$ guaiacol, $0.95 \mathrm{~mL}$; and enzyme extract, $50 \mu \mathrm{L}$. The enzyme activity was measured by monitoring the increase in absorbance at $470 \mathrm{~nm}$ during polymerization of guaiacol into tetraguaiacol. CAT activity was measured spectrophotometrically by following the consumption of $\mathrm{H}_{2} \mathrm{O}_{2}$ at $240 \mathrm{~nm}$ (Liu 2006). SOD was measured using SOD detection kit that was produced in Nanjing Jiancheng Bioengineering Institute. Assay was carried out according to the specification of the detection kit. MDA activity was measured according to Zhao (2000b). The enzyme extracts of 1.5 and $2.5 \mathrm{~mL}$ thiobarbituric acid (TBA, $0.5 \%$ ) were boiled for
$20 \mathrm{~min}$, and then centrifuged. Afterwards, the supernatant was measured spectrophotometrically at 532, 600, and $450 \mathrm{~nm}$.

\section{Statistical analysis}

Results were expressed as mean \pm standard deviation (SD). The obtained data were evaluated by Student's $t$ test compared with their corresponding control $\left(0 \mathrm{mg} \mathrm{L}^{-1}\right.$ $\mathrm{CuO}$ ) using Prism 5.0 statistical package. The statistical significance was considered at $\mathrm{p}<0.05$.

\section{Results and discussions}

\section{Characterization of CuO NPs and the particles in media}

The TEM image of CuO NPs and the particle size of the NPs in the culture media were showed in Fig. 1. The $\mathrm{CuO}$ NPs were near sphere shaped, and the diameter of individual NPs were basically less than $40 \mathrm{~nm}$.

The CuO NPs aggregated to form larger sizes in the culture media. The aggregations are likely driven by the divalent ions and low zeta potential (Griffitt et al. 2007). The divalent ion effect can be due to NP bridging via ionic bonds to form $\mathrm{NP}-M^{+}-\mathrm{NP}$ (where $M^{+}$is the salt cation), with $\mathrm{Na}^{+}$in the culture media, thereby promoting NP aggregation (Wang et al. 2011a). In addition, divalent cations such as $\mathrm{Mg}^{2+}$ and $\mathrm{Ca}^{2+}$ (also present in the culture media) have been shown to induce NP aggregation (Akaighe et al. 2012). Agglomerates forming a neck between two or more particles create an area of negative surface curvature, and nucleation occurs at this interface under equilibrium conditions. This action can result in the fusion of the agglomerates and a reduction in total particle surface area (Chang et al. 2012).

The zeta potentials of $\mathrm{CuO}$ NPs and bulk $\mathrm{CuO}$ in culture media are shown in Fig. 2. The zeta potentials of both nano- and bulk $\mathrm{CuO}$ were negatively charged in culture media. The zeta potentials of $\mathrm{CuO}$ NPs increased with the
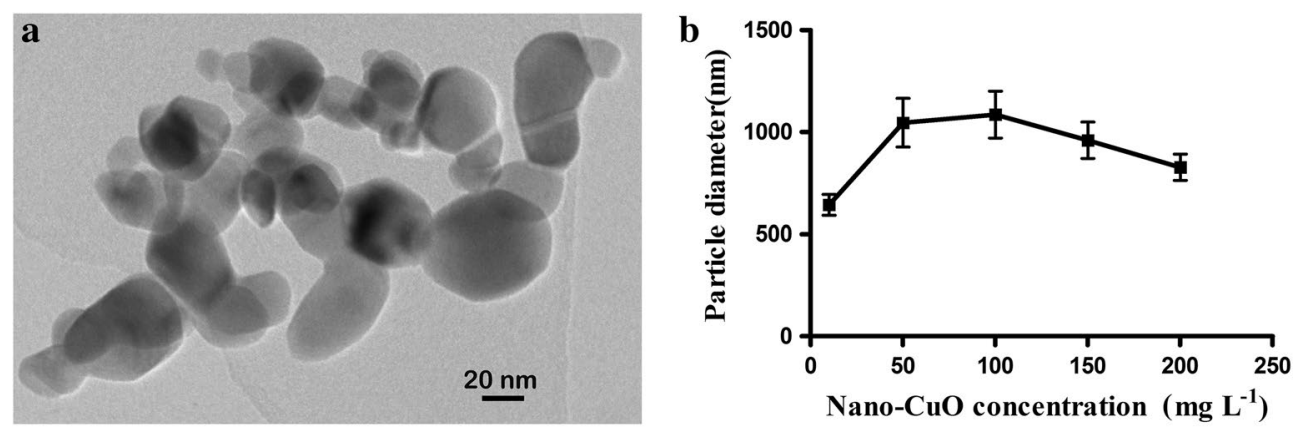

Fig. 1 TEM observation of CuO NPs (a) and size of CuO NPs aggregates in culture media (b) 


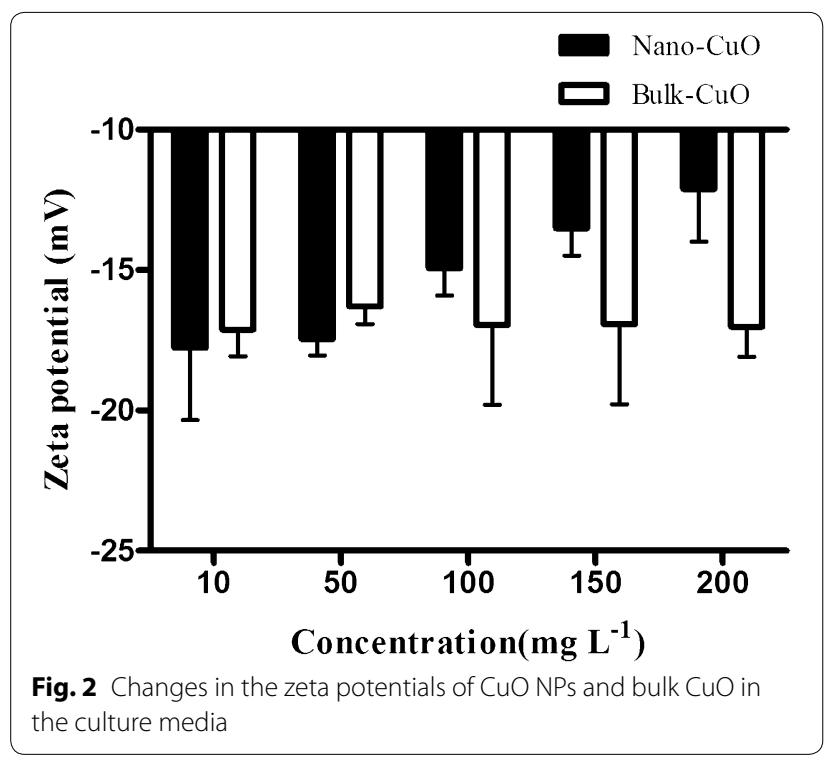

increase of NP concentration in media. The zeta potential absolute values of bulk $\mathrm{CuO}$ were higher than those of $\mathrm{CuO}$ NPs in the same concentration. The value of the zeta potential can be related to the stability of colloidal dispersion. Zeta potential indicates the degree of repulsion between adjacent, similarly charged particles in the dispersion. A high absolute value of the zeta potential of the particles in a solution indicates that the solution or dispersion has a high capacity to resist aggregation. When the zeta potential absolute value of the particles in a solution is low, attraction exceeds repulsion, and then the dispersion breaks and flocculates. The general dividing line between stable and unstable suspensions is generally considered at either +30 or $-30 \mathrm{mV}$. Particles with zeta potentials that are more positive than $+30 \mathrm{mV}$ or more negative than $-30 \mathrm{mV}$ are normally considered stable (Duman and Tunc 2009). The results of the present study indicate that the colloidal dispersion of these culture media with $\mathrm{CuO}$ NPs decreases when the NPs concentration is increased, and the stability of culture media-added bulk $\mathrm{CuO}$ was higher than that of culture media added with the same concentration $\mathrm{CuO}$ NPs. The particle diameter decreased with the increase in $\mathrm{CuO}$ NP concentration when the $\mathrm{CuO}$ NPs concentration was higher than $100 \mathrm{mg} / \mathrm{L}$, which can be the reason of the zeta potential changes in these culture media.

The $\mathrm{Cu}^{2+}$ concentrations released from $\mathrm{CuO}$ NPs in culture media at $24 \mathrm{~h}$ are illustrated in Fig. 3. Only a small amount of $\mathrm{Cu}^{2+}$ was released in our experiment, which should be attributed to the aggregation of $\mathrm{CuO}$ in these culture media (Wang et al. 2013). In addition, the $\mathrm{Cu}^{2+}$ released from $\mathrm{CuO}$ NPs in culture media is also associated with the $\mathrm{pH}$ of the culture media and other environmental conditions of the experiment.

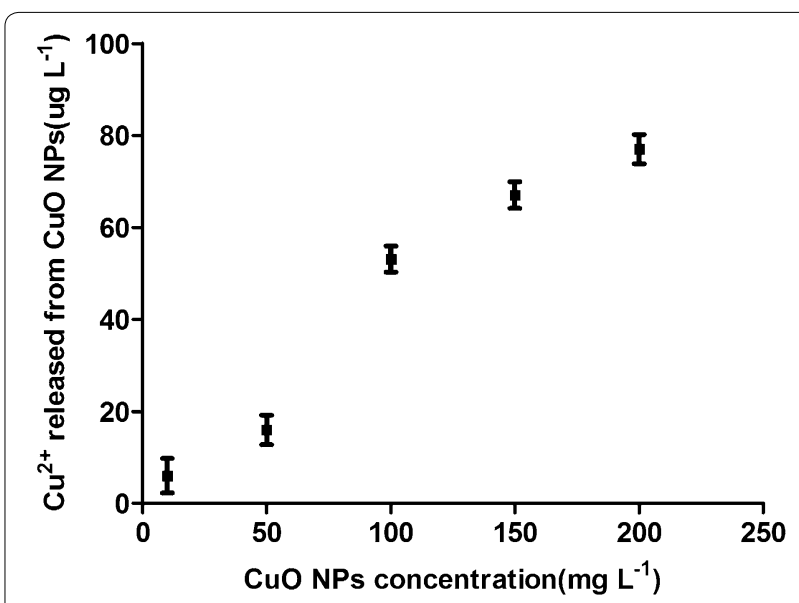

Fig. $3 \mathrm{Cu}^{2+}$ released from CuO NPs in culture media

Effects of CuO NPs, bulk CuO, and $\mathrm{Cu}^{2+}$ on the growth of $L$. minor

The effects of $\mathrm{CuO}$ NPs, bulk $\mathrm{CuO}$, and $2 \times$ concentration of $\mathrm{Cu}^{2+}$ released from $\mathrm{CuO}$ NPs on the frond number changes are shown in Fig. 4. The $\mathrm{CuO}$ NPs, bulk $\mathrm{CuO}$, and $\mathrm{Cu}^{2+}$ showed a negative effect on frond number of $L$. minor. The $\mathrm{CuO}$ NPs showed the highest negative effect among the three kinds of material. When the $\mathrm{CuO}$ NPs concentration was $10 \mathrm{mg} \mathrm{L}^{-1}$, the frond number changes of $L$. minor decreased significantly compared with that of the control. The second highest negative effect on frond number changes was caused by $2 \times$ concentration of $\mathrm{Cu}^{2+}$, and the $2 \times \mathrm{Cu}^{2+}$ released from $50 \mathrm{mg} \mathrm{L}^{-1} \mathrm{CuO}$ NPs showed a significantly negative effect on the frond number changes of $L$. minor. Therefore, the negative effect of $\mathrm{CuO}$ NPs on frond number changes of $L$. minor was only partly due to the $\mathrm{Cu}^{2+}$ released by $\mathrm{CuO}$ NPs in the media.

The effects of $\mathrm{CuO}$ NPs, bulk $\mathrm{CuO}$, and twice concentration $\mathrm{Cu}^{2+}$ released from $\mathrm{CuO}$ NPs in culture media on the

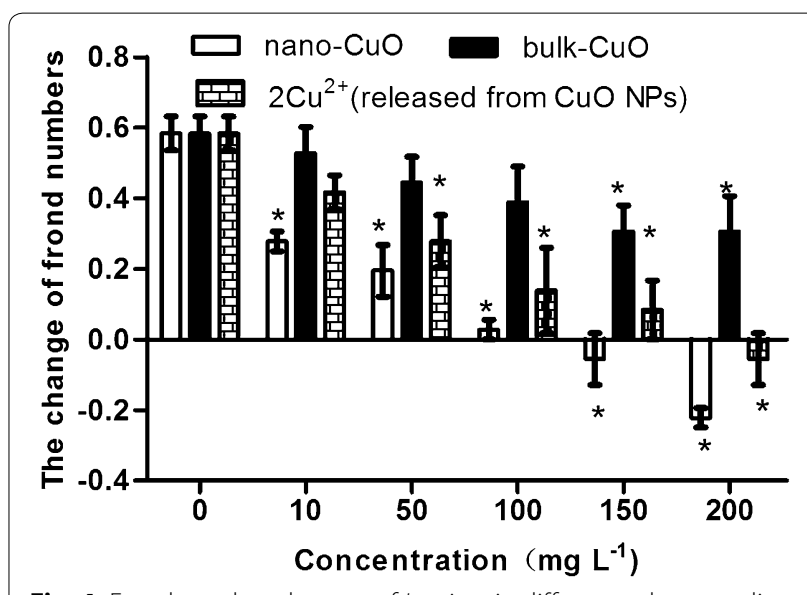

Fig. 4 Frond number changes of L. minor in different culture media 
root length of $L$. minor are shown in Fig. 5. CuO NPs, bulk $\mathrm{CuO}$, and $2 \times \mathrm{Cu}^{2+}$ concentration from $\mathrm{CuO}$ NPs negatively affect the root length of $L$. minor. The adverse effect of $\mathrm{CuO}$ NPs on root length was the greatest among the three treatments, followed by negative effect of $2 \times \mathrm{Cu}^{2+}$ concentration from $\mathrm{CuO}$ NPs. The three treatments showed significant effects on the root length of $L$. minor at $\geq 10 \mathrm{mg} \mathrm{L}^{-1}$. These factors significantly affected the root length of $L$. minor possibly because the plant-containing culture media were disturbed three times a day. The effect of $\mathrm{CuO}$ NPs on the micro-growth of another kind of duckweed (Landoltia punctata) and the uptake of $\mathrm{Cu}$ into plant tissue in comparison with a reference toxicant, $\mathrm{CuCl}_{2}$, have been studied (Gunawan et al. 2011), and CuO NPs are spontaneously synthesized in their study. Growth was inhibited (50\%) by a very low concentration of $1.0 \mathrm{mg} \mathrm{L}^{-1}$ $\mathrm{CuO}$ NPs after $96 \mathrm{~h}$ cultivation in petri dishes on a shaker. Such low concentration of CuO-NP can remarkably affect duckweed possibly because of the constant disturbance by the shaker. The roots of all kinds of duckweed are very tender, and thus, disturbance can easily harm their roots. The toxic materials can easily enter the root, resulting in significant damages to the root.

The fresh weights of $L$. minor in different culture media are shown in Fig. 6. All of the three copper treatments

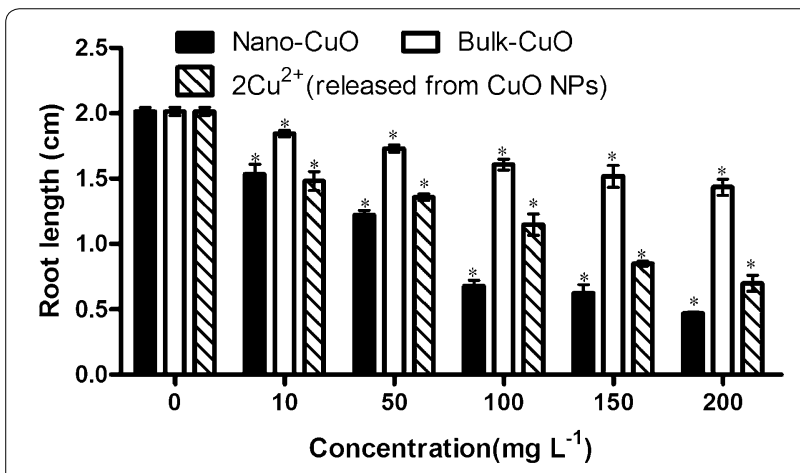

Fig. 5 Root length of $L$. minor in different culture media

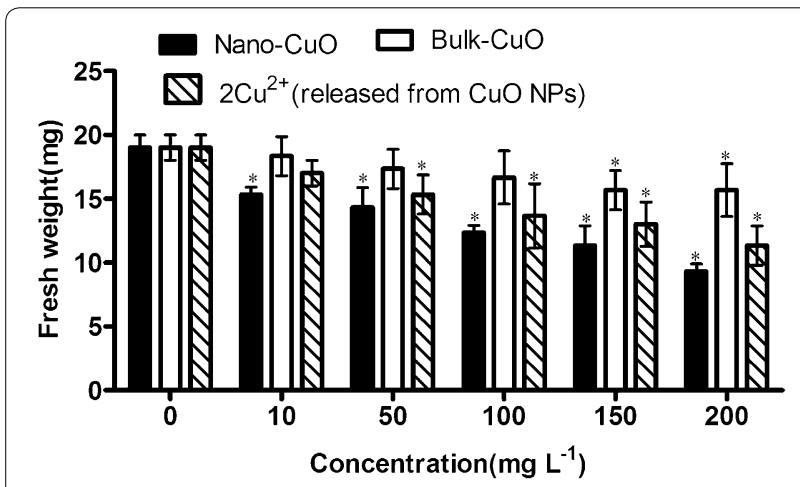

Fig. 6 Fresh weight of L. minor in different culture media showed negative effects on the fresh weight of L. minor. The negative effect of $\mathrm{CuO}$ NPs on fresh weight was the greatest among the three treatments, followed by $2 \times \mathrm{Cu}^{2+}$ concentration released from $\mathrm{CuO}$ NPs. The plant was consisted in two parts, namely, the frond and root. The fresh weight of this plant consisted mainly of the frond, because the root of this kind of plant is very tender and light.

The micro-growth of $L$. minor indicated that CuO NPs exhibited greater effect on the growth of $L$. minor than the bulk $\mathrm{CuO}$ in the same concentration. the effect of $\mathrm{CuO}$ NPs on $L$. minor growth partly because of the $\mathrm{Cu}^{2+}$ releasing in culture media.

\section{Effects of $\mathrm{CuO} N P s$, bulk $\mathrm{CuO}$, and $\mathrm{Cu}^{2+}$ on the chlorophyll content of $L$. minor fronds}

The chlorophyll content of $L$. minor frond changed with the increase in concentrations of the three material treatments (Fig. 7). The chlorophyll content of $L$. minor decreased with the increase in concentration of $\mathrm{CuO}$ NPs, bulk $\mathrm{CuO}$, and $2 \times \mathrm{Cu}^{2+}$ concentration released from $\mathrm{CuO}$ NPs in culture media. In addition, the decrease in L. minor frond chlorophyll content was not as remarkable as the decrease in L. minor microgrowth. Based on visual inspection, the frond pigment did not change significantly with the increase in $\mathrm{CuO}$ NPs, bulk $\mathrm{CuO}$, and $2 \times \mathrm{Cu}^{2+}$ concentration released from $\mathrm{CuO}$ NPs. Different metallic oxide NPs show different effects on plant chlorophyll content. When the $\mathrm{TiO}_{2}$ NPs concentration increased in culture media, the frond of $L$. minor became dark green, with red color appearing inside the fronds in our previous study (Song et al. 2012). In the presence of sunlight, chlorophyll converts carbon dioxide and water into oxygen and glucose. The insignificant decrease in L. minor chlorophyll content in low $\mathrm{CuO}$ NP concentration media indicated that the oxygen and glucose synthesis proceeds normally in these culture conditions.

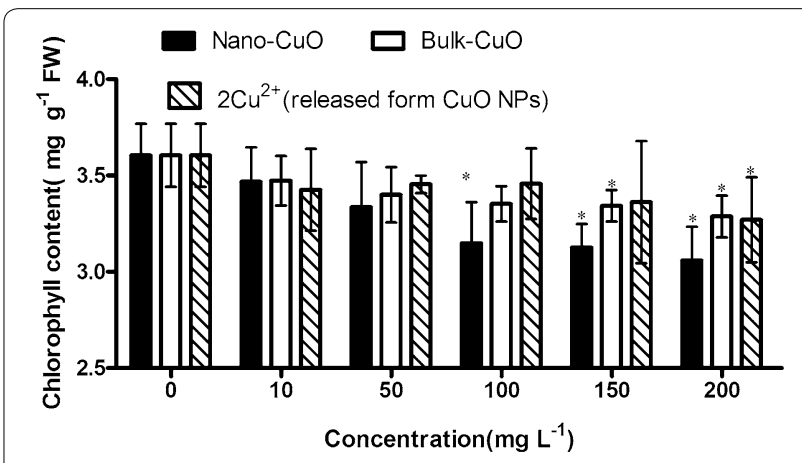

Fig. 7 Chlorophyll content of L. minor frond in different culture media 
Effects of $\mathrm{CuO} N P s$, bulk $\mathrm{CuO}$, and $\mathrm{Cu}^{2+}$ on antioxidant defense enzymes and MDA of $L$. minor

The effects of $\mathrm{CuO}$ NPs, bulk $\mathrm{CuO}$, and twice concentration released from $\mathrm{CuO}$ NPs in culture media on the protective enzymes (i.e., POD, CAT, and SOD) of L. minor was also examined, as well as the MDA content. The production of active oxygen species is a biochemical change that possibly occurs when plants are subjected to harmful stress conditions. The chloroplasts and mitochondria of plant cells are important intracellular generators of reactive oxygen species (ROS). Internal $\mathrm{O}_{2}$ concentration is high during photosynthesis, and chloroplasts are particularly prone to generate ROS; therefore, these cytotoxic ROS can remarkably disrupt normal metabolism through oxidative damage of lipids, nucleic acids, and proteins. Deleterious effects of ROS and lipid peroxidation products are counteracted by an antioxidant defense system (Pejic' et al. 2009). These damages can be examined by analyzing the changes of certain antioxidant enzymes, such as SOD, CAT, and POD.

The SOD activity of L. minor increased with the increase in $\mathrm{CuO}$ NPs, bulk $\mathrm{CuO}$, and $2 \times \mathrm{Cu}^{2+}$ concentration released from $\mathrm{CuO}$ NPs in culture media (Fig. 8). The SOD activity of $L$. minor significantly increased from $10 \mathrm{mg} \mathrm{L}^{-1} \mathrm{CuO}$ NP concentration in culture media compared with that of the control, and the SOD activity of $L$. minor was also significantly increased in $2 \times \mathrm{Cu}^{2+}$ concentration released from $10 \mathrm{mg} \mathrm{L}^{-1} \mathrm{CuO}$ NPs in culture media. The SOD activity of $L$. minor significantly increased until the bulk $\mathrm{CuO}$ concentration reached $100 \mathrm{mg} \mathrm{L}^{-1}$. SOD is an essential component of antioxidative defense system in plants. The enzyme is a major scavenger of $\mathrm{O}_{2}^{-}$and its enzymatic action results in the formation of $\mathrm{H}_{2} \mathrm{O}_{2}$ and $\mathrm{O}_{2}$. SOD performs a pivotal function in combating oxidative stress in plants, and a marked increase in SOD activity has been demonstrated to occur upon exposure to oxidative stress (Jalali-e-Emam et al. 2011). The plants in $\mathrm{CuO}$ NPs media accumulated $\mathrm{O}_{2}{ }^{-}$ in comparatively low concentration, and the release of $\mathrm{Cu}^{2+}$ in culture media acts as a very important factor in

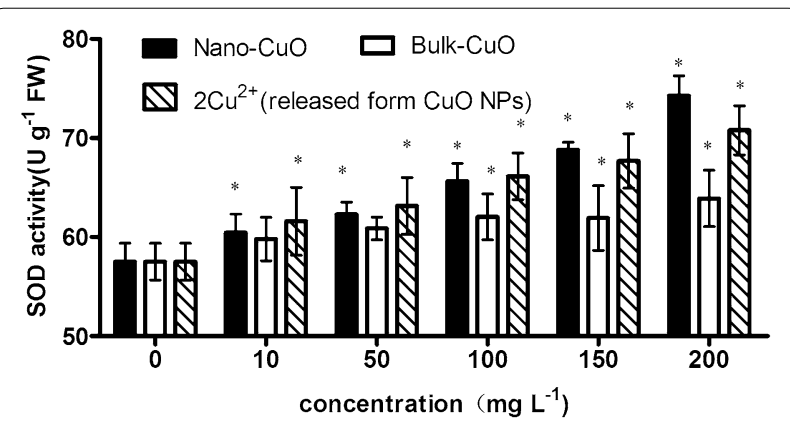

Fig. 8 SOD activity of $L$. minor in different culture media
SOD activity increase. L. minor accumulated a lower level of $\mathrm{O}_{2}{ }^{-}$in bulk $\mathrm{CuO}$ media than in $\mathrm{CuO}$ NPs.

The CAT activity of $L$. minor increased with the increase in $\mathrm{CuO}$ NPs, bulk $\mathrm{CuO}$, and $2 \times \mathrm{Cu}^{2+}$ concentration released from $\mathrm{CuO}$ NPs (Fig. 9). The CAT activity of L. minor showed a significant increase at $10 \mathrm{mg} \mathrm{L}^{-1} \mathrm{CuO}$ NP concentration and $2 \times \mathrm{Cu}^{2+}$ concentration released from the same $\mathrm{CuO}$ NP concentration in culture media. Bulk $\mathrm{CuO}$ did not show significant effect on the CAT activity of $L$. minor until the bulk $\mathrm{CuO}$ concentration reached $100 \mathrm{mg} \mathrm{L}^{-1}$. CAT is one of the most important enzymes that scavenge ROS in plant cells. This enzyme participates in the main defense system against accumulation and toxicity of hydrogen peroxide and can function in controlling $\mathrm{H}_{2} \mathrm{O}_{2}$ level in cells. It acts on $\mathrm{H}_{2} \mathrm{O}_{2}$ and converts it to water and oxygen. CAT often shows the same trend as that of SOD when an organism is under stress. A study showed that SOD increases and CAT decreases when an organism is exposed to stress (Cui and Zhao 2011); however, some reports show that SOD decreases and CAT increases in organisms exposed to stress ( $\mathrm{Li}$ et al. 2001; Sai Kachout et al. 2010). The activities of antioxidant defense enzymes are unstable and change with culture time. It is difficult to demonstrate if the plant can protect itself from environmental stress by using several antioxidant enzymes at a certain time. However, the activities of antioxidant defense enzymes often increase when the organism is under stress.

The POD activity of L. minor increased with the increase of $\mathrm{CuO}$ NPs, bulk $\mathrm{CuO}$, and $2 \times \mathrm{Cu}^{2+}$ concentration released from $\mathrm{CuO}$ NPs (Fig. 10). The POD activity of $L$. minor significantly increased compared with the control from $10 \mathrm{mg} \mathrm{L}^{-1}$ concentration of the three kinds of materials. POD belongs to the group of enzymes involved in the growth, development, and senescence processes of plants. POD affects lignin and ethylene synthesis, as well as the decomposition of indole-3-acetic acid, and is involved in resistance against pathogens and wound healing. The POD activity of $L$. minor with

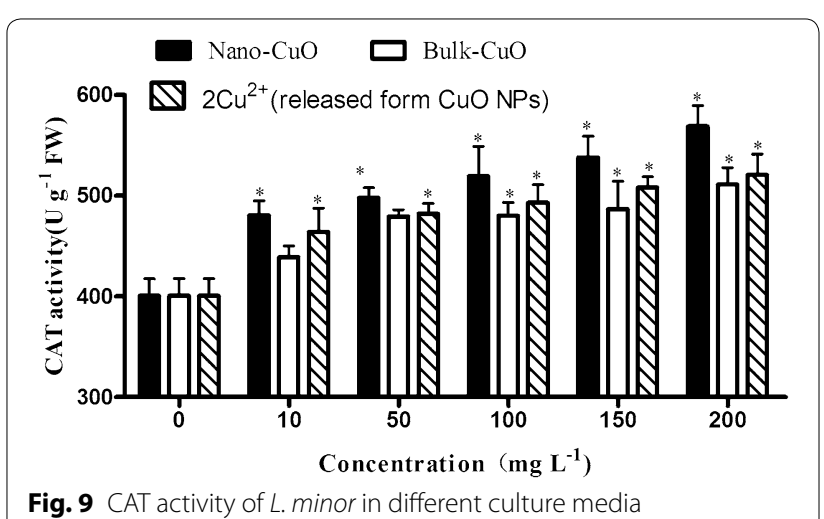




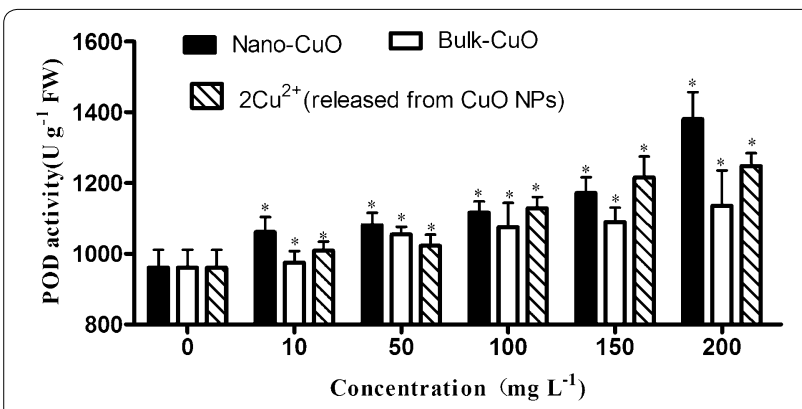

Fig. 10 POD activity of L. minor in different culture media

increase in $\mathrm{CuO}$ NPs, bulk $\mathrm{CuO}$, and $2 \times \mathrm{Cu}^{2+}$ concentration released from $\mathrm{CuO}$ NPs indicates that the $L$. minor in $\mathrm{CuO} \mathrm{NPs}$, bulk $\mathrm{CuO}$, and $2 \times \mathrm{Cu}^{2+}$ concentration released from $\mathrm{CuO}$ NPs encountered oxidant stress in these experiment condition. The POD activity significantly increased in such low concentrations of the three condition which can be attributed to the wound of the root. As mentioned, plant roots exposed to these treatments can be easily broken with disturbance.

The MDA content of $L$. minor increased with the increase of $\mathrm{CuO} N$ Ps, bulk $\mathrm{CuO}$, and $2 \times \mathrm{Cu}^{2+}$ concentration released from $\mathrm{CuO}$ NPs in culture media (Fig. 11). The MDA content was significantly increased compared with that of the control from $50 \mathrm{mg} \mathrm{L}^{-1} \mathrm{CuO} \mathrm{NP}$ concentration in culture media. The MDA content of L. minor cultured in media with twice concentration of $\mathrm{Cu}^{2+}$ that released from $\mathrm{CuO}$ NPs increase in culture media and bulk $\mathrm{CuO}$ was also significantly different compared with that of the control in relative higher concentration. MDA is the decomposition product of polyunsaturated fatty acids of biomembranes, and its increase is a result of significant accumulation under high antioxidant stress. MDA content serves as an indicator of the extent of lipid peroxidation and is an indirect reflection of the extent of cell damage (Wang et al. 2011b). The significantly increased MDA content of L. minor demonstrated that the plant cells encountered serious damage under the culture conditions.

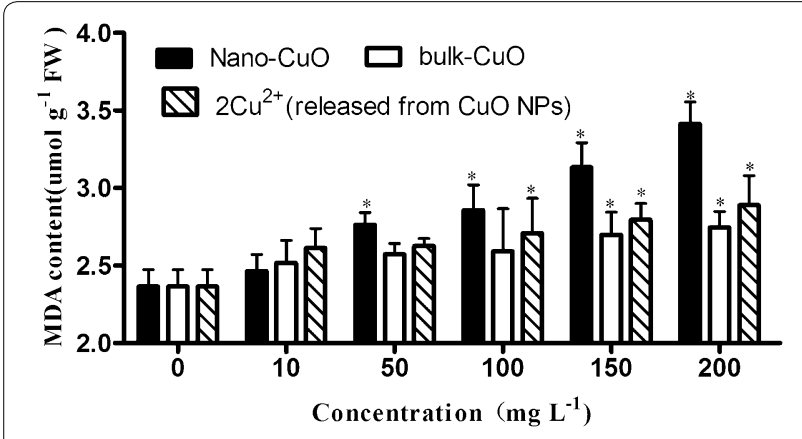

Fig. 11 MDA content of $L$. minor in different culture media

\section{Conclusions}

Copper dioxide NPs aggregated in culture media. The stability of media with bulk $\mathrm{CuO}$ was higher than that of media with the same concentration of $\mathrm{CuO}$ NPs. $\mathrm{CuO}$ NPs released $\mathrm{Cu}^{2+}$ in culture media.

$\mathrm{CuO}$ NPs, bulk $\mathrm{CuO}$, and $\mathrm{Cu}^{2+}$ decreased the growth of $L$. minor, and the effects of these three treatments on $L$. minor roots were more significant than the influence of the treatments on L. minor fronds. The effect of bulk $\mathrm{CuO}$ was not as remarkable as that of $\mathrm{CuO}$ NPs, and the effect of $\mathrm{CuO}$ NPs was partly due to the $\mathrm{Cu}^{2+}$ released from $\mathrm{CuO}$ NPs in the culture media.

L. minor cells exposed to $\mathrm{CuO}$ NPs accumulated more ROS compared with the plant cells exposed to the same concentration of bulk $\mathrm{CuO}$. The plant cells accumulated $\mathrm{ROS}$ in $\mathrm{CuO}$ NP media partly because $\mathrm{CuO}$ NPs released $\mathrm{Cu}^{2+}$ in the culture media. The plant cell encountered serious damage when the $\mathrm{CuO}$ NP concentration was $50 \mathrm{mg} \mathrm{L}^{-1}$.

\section{Author details}

${ }^{1}$ School of Medicine, Shihezi University, Shihezi 832000, China. ${ }^{2}$ Shanghai Key Laboratory of Atmospheric Particle Pollution Prevention (LAP3), Shanghai 200433, China. ${ }^{3}$ Research Center of Water Pollution Control Technology, Chinese Research Academy of Environment Sciences, Beijing 100012, China. ${ }^{4}$ Department of Life Science, Shandong University of Technology, Zibo 255049, China.

\section{Acknowledgements}

The present study received financial support from the National Natural Science Foundation of China (NSFC) (81560536), National Natural Science Foundation of China (NSFC) (81560614), Science and Technology Research Program of Shihezi University (RCZX201331), Science and Technology Research Program of Shihezi University(RCZX201445), Open Program of Shanghai Key Laboratory of Atmospheric Particle Pollution Prevention(LAP3) (FDLAP14003), Open Fund from Xinjiang Key Laboratory of Biological Resources and Genetic Engineering and Major Science (XJDX0201_2014_10) and Technology Program for Water Pollution Control and Treatment (2012ZX07201002).

\section{Authors' contributions}

GS, WH and YG designed carried out the experiments, YW designed the experiments, analyzed and interpreted data. LL, ZZ, QN and RM drafted the manuscript. LM and HW analyzed and interpreted data, and helped to draft the manuscript. All authors read and approved the final manuscript.

\section{Competing interests}

The authors declare that they have no competing interests.

Received: 3 November 2015 Accepted: 7 January 2016 Published online: 27 January 2016

\section{References}

Aitken RJ, Chaudhry MQ, Boxall ABA, Hull M (2006) Manufacture and use of nanomaterials: current status in the UK and global trends. Occup Med 56:300-306

Akaighe N, Depner SW, Banerjee S, Sharma VK, Sohn M (2012) The effects of monovalent and divalent cations on the stability of silver nanoparticles formed from direct reduction of silver ions by Suwannee River humic acid/natural organic matter. Sci Total Environ 441:277-289

Chang YN, Zhang MY, Xia L, Zhang J, Xing GM (2012) The Toxic Effects and Mechanisms of $\mathrm{CuO}$ and ZnO Nanoparticles. Materials 5:2850-2871. doi:10.3390/ma5122850 
Chowdhuri A, Gupta V, Sreenivas K, Kumar R, Mozumdar S, Patanjali PK (2004) Response speed of $\mathrm{SnO}_{2}$-based $\mathrm{H}_{2} \mathrm{~S}$ gas sensors with $\mathrm{CuO}$ nanoparticles. Appl Phys Lett 84:1180-1182

Clément L, Hurel C, Marmier N (2013) Toxicity of TiO 2 nanoparticles to cladocerans, algae, rotifers and plants - effects of size and crystalline structure. Chemosphere 90:1083-1090

Cui Y, Zhao N (2011) Oxidative stress and change in plant metabolism of maize (Zea mays L.) growing in contaminated soil with elemental sulfur and toxic effect of zinc. Plant Soil Environ 57:34-39

Dar MA, Kim YS, Kim WB, Sohn JM, Shin HS (2008) Structural and magnetic properties of $\mathrm{CuO}$ nanoneedles synthesized by hydrothermal method. Appl Surf Sci 254:7477-7481

Duman O, Tunc S (2009) The colloidal stability of raw bentonite deformed mechanically by ultrasound. Micropor Mesopor Mater 117:331-338

Griffitt RJ, Weil R, Hyndman KA, Denslow ND, Powers K, Taylor D, Barber DS (2007) Exposure to copper nanoparticles causes gill injury and acute lethality in Zebrafish (Danio rerio). Environ Sci Technol 41:8178-8186

Gunawan C, Teoh WY, Marquis CP, Amal R (2011) Cytotoxic origin of copper (II) oxide nanoparticles: comparative studies with micron-sized particles, leachate, and metal salts. ACS Nano 5:7214-7225

Jalali-e-Emam SMS, Alizadeh B, Zaefizadeh M, Zakarya RA, Khayatnezhad M (2011) Superoxide dismutase (SOD) activity in $\mathrm{NaCl}$ stress in salt-sensitive and salt-tolerance genotypes of Colza (Brassica napus L.). Middle East J Sci Res 7:7-11

Jammi S, Sakthivel S, Rout L, Mukherjee T, Mandal S, Mitra R, Saha P, Punniyamurthy T (2009) CuO nanoparticles catalyzed C-N, C-O, and C-S crosscoupling reactions: scope and mechanism. J Org Chem 74:1971-1976

Kahru A, Dubourguier H (2010) From ecotoxicology to nanoecotoxicology. Toxicology 269:105-119

Li M, Wang GX (2001) Effect of drought stress on activities of cell defense enzymes and lipid peroxidation in Glycyrrhiza uralensis seedlings. Acta Ecol Sin 22:503-507

Li Y, Zhang W, Niu J, Chen Y (2012) Mechanism of photogenerated reactive oxygen species and correlation with the antibacterial properties of engineered metal-oxide nanoparticles. ACS Nano 6:5164-5173

Liu W (2006) Determining the activities of catalase (CAT) and peroxidase (POD). In: Chen JX, Wang XF (eds) Manual of Plant Physiology Experiment. South China University of Technology Press, China, pp 72-73

Michael C, Hans-toni R (2002) Phytotoxicity of coloured substances: is Lemna Duckweed an alternative to the algal growth inhibition test? Chemosphere 49:9-15

Miralles P, Church TL, Harris AT (2012) Toxicity, uptake, and translocation of engineered nanomaterials in vascular plants. Environ Sci Technol 46:9224-9239

Mohan BS, Hosetti BB (1999) Aquatic plants for toxicity assessment. Environ Res Sec A 81:259-274

Nair R, Varghese SH, Nair BG, Maekawa T, Yoshuda Y, Kumar DS (2010) Nanoparticulate material delivery to plants. Plant Sci 179:154-1643
Pejic' S, Todorovic' A, Stojiljkovic' V, Kasapovic' J, Pajovic' SB (2009) Antioxidant enzymes and lipid peroxidation in endometrium of patients with polyps, myoma, hyperplasia and adenocarcinoma. Reprod Biol Endocrinol 7:149

Robert LM (2012) Nano-technology and nano-toxicology. Emerg Health Threats J 5:17508

Sai Kachout S, Ben Mansoura A, Leclerc JC, Mechergui R, Rejeb MN, Ouerghi Z (2010) Effect of heavy metals on antioxidant activities of Atriplex Hortensis and $A$. Rosea Ejeafche 9:444-457

Song GL, Hou WH, Wang QH, Wang JL, Jin XC (2006) Effect of low temperature on eutrophicated waterbody restoration by Spirodela polyrhiza. Bioresour Technol 97:1865-1869

Song GL, Gao Y, Wu H, Hou WH, Zhang CY, Ma HQ (2012) Physiological effect of anatase $\mathrm{TiO}_{2}$ nanoparticles on Lemina Minor. Environ Toxicol Chem 31:2147-2152

Tkalec M, Željka VC, Regula I (1998) The effect of oil industry “high density brines" on duckweed Lemna minor L. Chemosphere 37:2703-2715

Wang D, Tejerina B, Lagzi I, Kowalczyk B, Grzybowski BA (2011a) Bridging interactions and selective nanoparticle aggregation mediated by monovalent cations. ACS Nano 5:530-536

Wang HF, Zhong XH, Shi WY, Guo B (2011 b) Study of malondialdehyde (MDA) content, superoxide dismutase (SOD) and glutathione perox-idase (GSHPx) activities in chickens infected with avian infectious bronchitis virus. Afr J Biotechnol 10:9213-9217

Wang LY, Wang M, Peng CS, Pan JF (2013) Toxic Effects of Nano-CuO, Micro$\mathrm{CuO}$ and $\mathrm{Cu}^{2+}$ on Chlorella sp. J Environ Prot 4:86-91. doi:10.4236/ jep.2013.41b016

Xia J, Zhao HZ, Lu GH (2013) Effects of selected metal oxide nanoparticles on multiple biomarkers in Carassius auratus. Biomed Environ Sci 26:742-749

Yin M, Wu CK, Lou Y, Burda C, Koberstein JT, Zhu Y, O'Brien S (2005) Copper oxide nanocrystals. J Am Chem Soc 127:9506-9511

Žaltauskaitè J, Norvilaitè R (2013) Phytotoxicity of amidosulfuron (sulfonylureas herbicide) to aquatic macrophyte Lemna minor L. Biologija 59:165-174

Zhang Q, Xu L, Wang J, Sabbioni E, Piao L, Di Gioacchino M, Niu Q (2013) Lysosomes involved in the cellular toxicity of nano-alumina: combined effects of particle size and chemical composition. J Biol Regul Homeost Agents 27:365-375

Zhao SJ (2000a) Detection of chlorophyll pigment. In: Zou Y (ed) Manual of plant physiology experiment. Chinese Agriculture Press, China, pp 72-75

Zhao SJ (2000b) Detection of the activity of MDA in plant tissue. In: Zou Y (ed) Manual of plant physiology experiment. Chinese Agriculture Press, China, pp 173-174

Zhao J, Wang Z, Liu X, Xie X, Zhang K, Xing B (2011) Distribution of CuO nanoparticles in juvenile carp (Cyprinus carpio) and their potential toxicity. J Hazard Mater 197:304-310

\section{Submit your manuscript to a SpringerOpen ${ }^{\circ}$ journal and benefit from:}

- Convenient online submission

- Rigorous peer review

- Immediate publication on acceptance

- Open access: articles freely available online

- High visibility within the field

- Retaining the copyright to your article

Submit your next manuscript at springeropen.com 